\title{
No detection of enteroviral genome in the myocardium of patients with arrhythmogenic right ventricular cardiomyopathy
}

Fiorella Calabrese, Annalisa Angelini, Gaetano Thiene, Cristina Basso, Andrea Nava, Marialuisa Valente

\begin{abstract}
Aims-Despite the evidence of familial occurrence, chromosomal gene mapping, and apoptosis as a mechanism of myocyte death, the aetiopathogenesis of arrhythmogenic right ventricular cardiomyopathy (ARVC) remains speculative. Because of the frequent histological finding of focal inflammatory infiltrates, the hypothesis of an infective myocarditis aetiology has been put forward. The aim of this investigation was to test this hypothesis. The presence of enteroviruses was investigated by a highly sensitive and specific molecular technique.
\end{abstract}

Methods-Endomyocardial tissue samples from 20 patients with ARVC (11 male, nine female; mean age, 40 years; SD, 16) and 20 control subjects with other cardiac diseases were analysed using reverse transcription and nested polymerase chain reaction (PCR). Myocardial samples obtained from four patients with enteroviral myocarditis and coxsackie $B 3$ virus infected cells were used as positive controls. Results-Endomyocardial biopsy was diagnostic for ARVC in all patients: myocardial atrophy was seen, with less than $45 \%$ residual myocytes. Foci of inflammatory infiltrates were seen in four biopsies, and the cells were identified by immunohistochemistry as mainly T cells. All samples, from both patients with ARVC and subjects with other cardiac diseases, were negative for enteroviral genome by means of nested PCR.

Conclusion-These findings indicate that enteroviruses are not involved in the aetiopathogenesis of ARVC. Future molecular studies should investigate the presence of other infective agents, as well as their possible role in triggering apoptosis. (f Clin Pathol 2000;53:382-387)

Keywords: arrhythmogenic right ventricular cardiomyopathy; myocarditis; enterovirus; molecular biology

Arrhythmogenic right ventricular cardiomyopathy (ARVC) is a primary heart muscle disease that is now listed among cardiomyopathies in the WHO classification. ${ }^{1}$ It is characterised pathologically by segmental or diffuse fibrofatty replacement of the right ventricular myocardium, ${ }^{2-4}$ and clinically by ventricular arrhythmias that can lead to sudden death..$^{5-8}$ The disease is often familial with autosomal dominant inheritance and variable penetrance ${ }^{9}{ }^{10}$; five loci have been identified, two mapping to chromosomes 14 , one to chromosome 1 , one to chromosome 2 , and one to chromosome 3 , suggesting genetic and clinical heterogeneity. ${ }^{11-15}$ Recently, a recessive form associated with palmo-plantar keratosis has also been described mapping to chromosome 17. ${ }^{16}$ However, the specific gene defects, as well as the defective encoded proteins, have not yet been identified. Apoptosis has been shown to be a mechanism of myocyte death either at necropsy ${ }^{17}$ or biopsy. ${ }^{18}$

The finding of inflammatory infiltrates ${ }^{419}$ in approximately two thirds of cases supports the hypothesis that ARVC might be associated with infective myocarditis, which either triggers the onset or worsens the natural history of the disease in patients carrying the ARVC genome. Enteroviruses, especially coxsackie B virus, have been reported to be the most common agents of human myocarditis. ${ }^{20}$ To date, the presence of enterovirus has been investigated only in a small number of patients with ARVC. ${ }^{21-24}$ We performed molecular analysis to identify the enteroviral genome in endomyocardial biopsy specimens using the nested polymerase chain reaction (PCR), a methodology with high sensitivity and specificity. ${ }^{2125}$

\section{Material and methods}

The clinical diagnosis of ARVC was performed in 20 consecutive patients according to the criteria of McKenna et $a l,{ }^{26}$ and confirmed by endomyocardial biopsy according to the histological parameters of Angelini et al. ${ }^{27}$ There were 11 male and nine female patients, mean age 40 (SD, 16) years. Baseline electrocardiography (ECG) showed inverted $\mathrm{T}$ waves on right precordial leads in eight patients, monomorphic or polymorphic left bundle branch block ventricular arrhythmias in 16, and atrial flutter or fibrillation in four. A previous syncopal episode had occurred in 10 patients. A family history for ARVC was ascertained in nine patients. Five patients had a recent clinical onset of the disease ( $\leqslant 6$ months) and in four patients there was a history of a flu like syndrome. Serological studies, including neutralising enteroviral antibodies, were not diagnostic in any of the patients.

The control group included 20 patients with other cardiac diseases: ischaemic heart disease in five, valvular disease in five, restrictive cardiomyopathy in five, amyloid cardiomyopathy in two, sarcoidosis in two, and cardiomy- 
Table 1 Clinicopathological features and detection of enterovirus by nested polymerase chain reaction (PCR)

\begin{tabular}{llllll}
\hline Disease & No. cases & $\begin{array}{l}\text { Sex } \\
(M / F)\end{array}$ & $\begin{array}{l}\text { Mean age } \\
(S D)\end{array}$ & $\begin{array}{l}\text { Clinical history } \\
\text { duration }<6 \text { months }\end{array}$ & $\begin{array}{l}\text { Nested PCR } \\
\text { positive samples }\end{array}$ \\
\hline ARVC & 20 & $11 / 9$ & $40(16)$ & $5 / 12$ & 0 \\
IHD & 5 & $4 / 1$ & $50.6(7.6)$ & $1 / 5$ & 0 \\
RC & 5 & $3 / 2$ & $41(5)$ & $0 / 2$ & 0 \\
VHD & 5 & $2 / 0$ & $56(1.4)$ & $0 / 2$ & 0 \\
Amyloidosis & 2 & $1 / 1$ & $59(5.6)$ & $0 / 1$ & 0 \\
CR-A & 1 & $0 / 1$ & 71 & $0 / 0$ & 0 \\
Sarcoidosis & 2 & $1 / 1$ & $54(8.4)$ & $0 / 1$ & 0 \\
Myocarditis & 4 & $3 / 1$ & $22.2(23)$ & $3 / 4$ & 4 \\
\hline
\end{tabular}

ARVC, arrhythmogenic right ventricular cardiomyopathy; CR-A, radiation associated cardiomyopathy; IHD, ischaemic heart disease; RC, restrictive cardiomyopathy; VHD, valvular heart disease.

Table 2 Sequence and localisation of the primers used in our study

\begin{tabular}{llll}
\hline Primer & Primer sequence (5' to 3') & $\begin{array}{l}\text { Nucleotide position of } \\
\text { primers }\end{array}$ & $\begin{array}{l}\text { Length of } \\
\text { amplicon }\end{array}$ \\
\hline OL252 & GGCCCCTGAATGCGGCA & $453-472$ & $745 \mathrm{bp}$ \\
OL68 & GGGACCTTCCACCACNC & $1178-1198$ & $215 \mathrm{bp}$ \\
OL24 & CTACTTTGGGTGTCCG & $545-561$ & $234 \mathrm{bp}^{\star}$ \\
OL253 & GATAC(T/C)TGAGCNCT & $743-760$ & \\
3GPDH1 & AGGTGAAGGTCGGAGG & $1460-1480$ & \\
3GPDH2 & GCTCCTGGAAGATGGTG & $3542-3412$ & \\
\hline
\end{tabular}

* These primers were designed around introns to produce a fragment of $2086 \mathrm{bp}$ from DNA and 234 from RNA.

3GPDH, glyceraldehyde-3-phosphate dehydrogenase.

opathy as a result of radiation in one. Table 1 shows the clinicopathological features of the patients and control subjects enrolled in our study. Four cases of myocarditis, previously diagnosed by PCR as enteroviral myocarditis, and coxsackie virus B3 infected $\mathrm{KB}$ cells (cell line derived from oral, human, epidermoid carcinoma) were used as positive controls.

At least six samples $(\sim 1 \mathrm{mg})$ were obtained from all patients; four were fixed in formalin, whereas two samples were immediately frozen in liquid nitrogen and stored at $-70^{\circ} \mathrm{C}$. Molecular studies were performed using both buffered formalin fixed and frozen tissue samples. It has been shown that PCR can be used successfully for the detection of some infectious agents, even when myocardial tissues have been formalin fixed. ${ }^{28}{ }^{29}$ Blood samples collected at the same time or shortly after were also analysed.

HISTOLOGICAL AND IMMUNOHISTOCHEMICAL ANALYSES

Sections $(6 \mu \mathrm{m}$ thick) of paraffin wax embedded tissues were stained according to the haematoxylin and eosin and Azan Mallory techniques.

To characterise the cellular infiltrates, paraffin wax embedded sections were stained with a panel of monoclonal antibodies: CD45 for leucocyte common antigen, CD45RO for T cells, CD43 for $\mathrm{T}$ cells and myeloid lineage, CD20 for B cells, and CD68 for macrophages (all from Dako, Glostrup, Denmark), according to the avidin-biotin peroxidase complex (ABC) method (Vector, Burlingame, California, USA).

RNA EXTRACTION

Frozen and formalin fixed biopsies were homogenised in an RNAzol solution $(0.8 \mathrm{ml})^{30}$ by means of a motorised pestle. The pestle was changed between each sample. Chloroform/ isoamyl alcohol solution $(80 \mu \mathrm{l}$ of $49 / 1$ dilu-
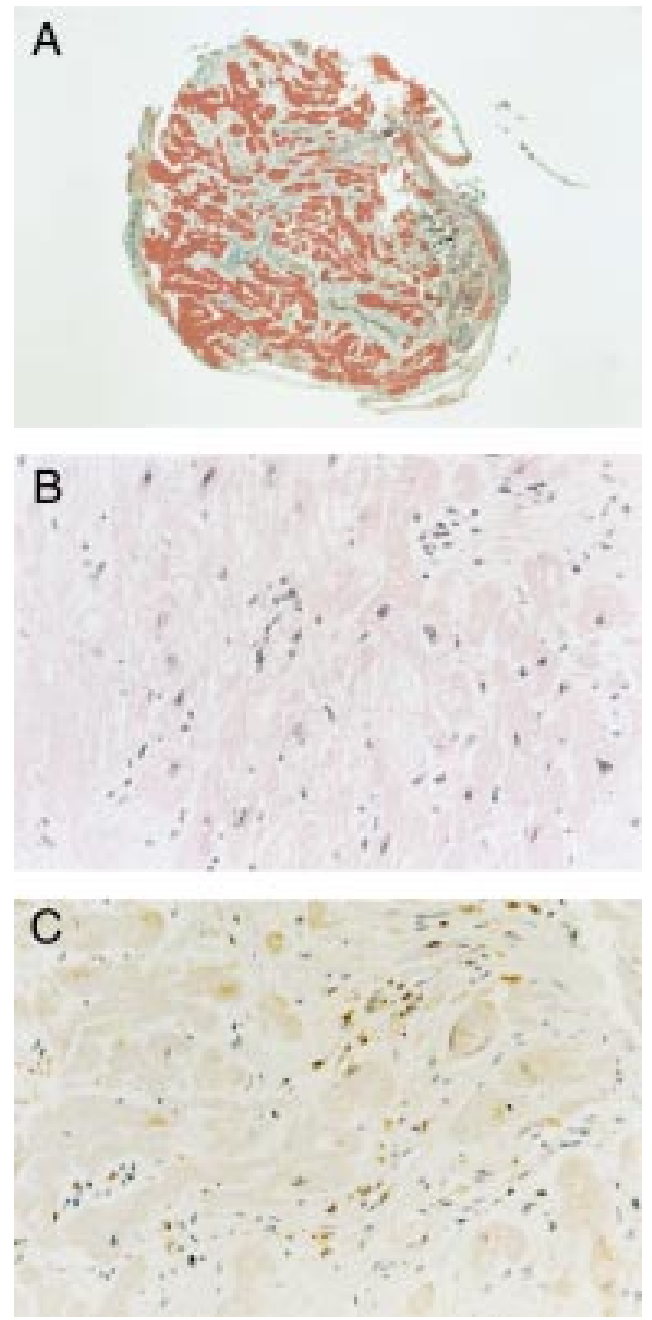

Figure 1 Endomyocardial biopsy in a 22 year old male patient with arrhythmogenic right ventricular cardiomyopathy (ARVC) and a family history of juvenile sudden death and ARVC and recurrent left bundle branch block-type ventricular arrhythmias. (A) Endomyocardial biopsy sample showing fibrous replacement of the right ventricular myocardium (Azan stain; magnification, $\times 45$ ). (B) High power image of $(A)$ showing scattered mononuclear inflammatory infiltrates (haematoxylin and eosin; magnification, $\times 240$ ). (C) Immunohistochemistry of the same section showing CD45RO positive cells consistent with $T$ cells (avidin-biotin peroxidase complex stain; magnification, $\times 240)$.

tion) was added and samples were kept on ice for 15 minutes before centrifuging at $12000 \times g$. The top aqueous phase was placed into a new tube, $400 \mu \mathrm{l}$ isopropyl alcohol was added to precipitate the nucleic acid, and the solution was left at $-20^{\circ} \mathrm{C}$ for at least three hours before centrifuging at $12000 \times g$ for 15 minutes. The RNA pellet was washed with $75 \%$ ethanol, dried, and resuspended in $10 \mu \mathrm{l}$ DEPC distilled $\mathrm{H}_{2} \mathrm{O}$.

OLIGONUCLEOTIDES

The oligonucleotides used to ascertain the quality of the extracted RNA were complementary to glyceraldehyde-3-phosphate dehydrogenase (3GPDH) mRNA (table 2). These primers amplify all human RNA samples. ${ }^{31}$ Two set of primers were used for enterovirus nested PCR analysis: OL 68 and OL 252 for the first stage PCR and OL24 and 253 for the 
A

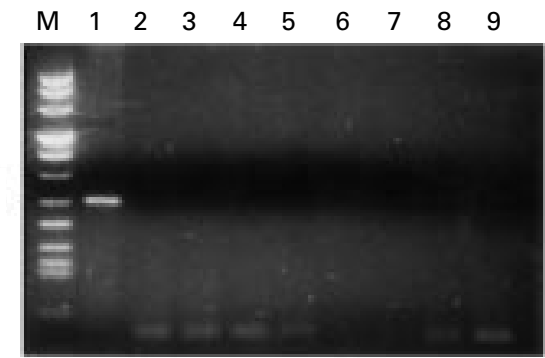

B

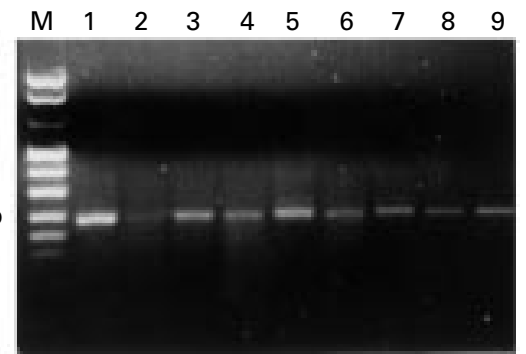

$234 \mathrm{bp}$

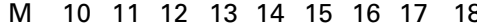
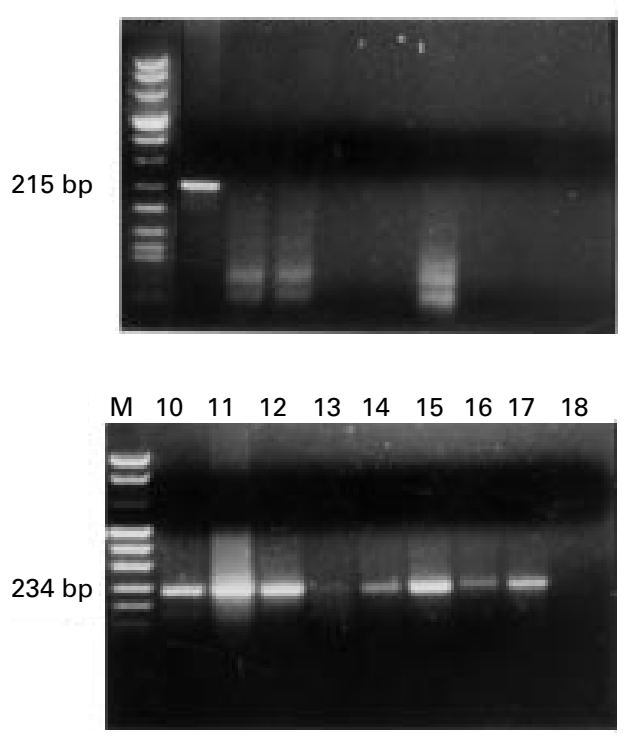

Figure 2 (A) Gel electrophoresis results of reverse transcription nested PCR for enterovirus in patients with arrhythmogenic right ventricular cardiomyopathy (ARVC) and controls. (B) Glyceraldehyde-3-phosphate dehydrogenase PCR products of the same patients. M, molecular size marker (DNA molecular weight marker VIII); lane 1, positive control amplification of $K B$ coxsackie virus B3 infected cells; lanes 2-9, patients with ARVC (frozen tissues); lanes 11-14, patients with ARVC (fixed tissues); lane 10, patient with myocarditis; lane 15, patient with ischaemic heart disease; lane 16, patient with restrictive cardiomyopathy; lane 17, patient with amyloidosis; lane 18, negative control with no DNA template.

nested PCR. These were specific to a region common to several enteroviruses (their sequences and predicted PCR amplicon sizes are given in table 2). The primers were the same of those reported by Khan et al..$^{25}$

REVERSE TRANSCRIPTION

For viral genome RNA detection the total RNA extracted (at least $1 \mu \mathrm{g}$ ) from the clinical biopsy was reverse transcribed in a total volume of $50 \mu \mathrm{l}$ containing the following components: $50 \mathrm{mM}$ Tris/ $\mathrm{HCl}$ (pH 8.3), $70 \mathrm{mM} \mathrm{KCl}$, $3 \mathrm{mM} \mathrm{MgCl}, 10 \mathrm{mM}$ dithiothreitol, $0.5 \mathrm{mM}$ dNTPs (Pharmacia, Cambridge, UK), 25 units of human placental ribonucleoside inhibitor (Amersham International, Little Chalfont, Buckinghamshire, UK), primer OL68 $(0.1 \mathrm{nmol})$, and 200 units of Superscript II RNase $\mathrm{H}$ free reverse transcriptase (Gibco BRL, Paisley, UK). The reaction was carried out at $37^{\circ} \mathrm{C}$ for one hour.

POLYMERASE CHAIN REACTION

For the first PCR assay, $15 \mu l$ of each reverse transcribed sample was amplified in a total volume of $100 \mu \mathrm{l}$. The following conditions were used: $10 \mathrm{mM}$ Tris/ $\mathrm{HCl}$ (pH 8.3), $50 \mathrm{mM} \mathrm{KCl}$, $1.5 \mathrm{mM} \mathrm{MgCl}_{2}, 0.2 \mathrm{mM}$ dNTPs, primers OL252 and OL68 (0.1 nmol each), and 2.5 units of Taq polymerase (Boehringer Mannheim, Mannheim, Germany). Thirty five cycles were carried out as follows: denaturation for 1.5 minutes at $94^{\circ} \mathrm{C}$, primer annealing for 1.5 minutes at $55^{\circ} \mathrm{C}$, and template extension for three minutes at $72^{\circ} \mathrm{C}$. An aliquot of $5 \mu \mathrm{l}$ of the first amplification reaction was amplified further with the nested pair (OL24 and OL253, $0.1 \mathrm{nmol}$ each) in $100 \mu \mathrm{l}$ of reaction mixture. The reaction was subjected to the above described amplification times except for a reduction of the template extension time to two minutes. Two other annealing temperatures $-58^{\circ} \mathrm{C}$ (high stringency) and $50^{\circ} \mathrm{C}$ (low stringency) - were used in each PCR reaction. The amplicons were then electrophoresed on a $3 \%$ NuSIEVE $/ 1 \%$ Seakem TM agarose gel (FMC Bio Products, Rockland, Maine, USA) and stained with ethidium bromide.

Before performing nested PCR for enterovirus, an independent reverse transcription PCR (RT-PCR) amplification for 3GPDH was performed using the previously described protocol. ${ }^{31}$

Precautions were taken to avoid false positives as a result of contamination by PCR product carry over, including physical separation procedures, the use of aliquoted reagents and positive displacement pipettes, and ultraviolet irradiation of non-disposable equipment.

\section{SENSITIVITY}

To assess the sensitivity of the nested PCR, serial 10-fold dilutions of the supernatant of coxsackie virus B3 infected $\mathrm{KB}$ cells were used to infect monolayers of $\mathrm{KB}$ cells to determine virus titre by the plaque assay technique. ${ }^{32}$ The amount of virus corresponding to a single plaque forming units (PFU) was serially diluted and aliquots with $10^{-1}$ to $10^{-6}$ were mixed with approximately $1 \mathrm{mg}$ of normal mouse myocardial tissue. From each sample, total RNA was extracted, reverse transcribed, and amplified as described above. A positive result on amplification was clearly evident with dilutions greater than $10^{-2}$ PFU. Most of the samples with $10^{-3}$ (nine of 10) showed a positive result and conversely most of the dilutions with $10^{-4}$ (one of 10) gave a negative 
result. Applying the minimum $\chi^{2}$ methods described by Taswell ${ }^{33}$ to our data, it was found that our amplification technique can detect about 1800 single RNA molecules/PFU. Other authors have obtained similar results using nested PCR for enterovirus detection. ${ }^{34}$

\section{Results}

HISTOLOGICAL AND IMMUNOHISTOCHEMICAL FINDINGS

At endomyocardial biopsy, a diagnostic amount of fibro-fatty tissue causing myocardial atrophy with residual myocytes less than $45 \%{ }^{27}$ was found in all samples. Residual myocytes were scattered throughout the fatty or fibrofatty infiltration (fig $1 \mathrm{~A}$ and $\mathrm{B}$ ) and often showed pycnotic nuclei and cytoplasmic shrinkage. Foci of inflammatory infiltration were seen in four biopsies. Immunohistochemical staining revealed mixed inflammatory infiltrates (CD 45, CD 45RO, CD43, and CD68 positive cells) with a high prevalence of $\mathrm{T}$ cells (fig $1 \mathrm{C}$ ).

ADEQUACY OF NUCLEIC ACID EXTRACTION All samples were analysed using 3GPDH primers to ensure adequate nucleic acid extraction. The mRNA of this housekeeping gene was amplified successfully from all clinical samples.

DETECTION OF ENTEROVIRUS IN PATIENTS WITH ARVC AND CONTROLS

Table 1 summarised the results of the nested PCR analyses performed in each case. The endomyocardial biopsies from patients with ARVC and control subjects were all negative by nested PCR (fig 2). Negative results obtained in each sample were analysed twice in different experiments, and nested PCR was performed under different stringency conditions.

Coxsackie virus type B neutralising antibodies were not increased in the serum of any of the patients. Blood samples did not reveal any amplification product.

Amplification was always obtained in samples from patients with coxsackie B3 virus myocarditis as well as in coxsackie virus B3 infected KB cells.

\section{Discussion}

Despite the evidence of familial occurrence, ${ }^{9}{ }^{10}$ chromosomal gene mapping, ${ }^{11-16}$ and apoptosis as a mechanism of progressive myocyte death, ${ }^{17} 18$ the aetiopathogenesis of ARVC remains speculative. ${ }^{3}$ The frequent finding of inflammatory infiltrates in up to two thirds of cases at histology supports the hypothesis that ARVC might be inflammatory in origin. ${ }^{4}$ In the clinical series of Blomström-Lundqvist et al, ${ }^{35}$ $40 \%$ of patients with ARVC developed ventricular tachycardia, in the setting of an infectious disorder with a clinical picture and laboratory tests consistent with acute myocardial damage.

Interestingly, some authors reported the association of ARVC and myocarditis even in the same family. ${ }^{22} 3637$ Such findings suggest a link between inherited and acquired ("inflammatory") forms of the disease. Genetic factors might play a role not only in influencing susceptibility to infections or to autoimmunity, but also in determining the site of cardiac involvement, namely the epimyocardium of the right ventricle.

Various infectious agents have been claimed to be involved in ARVC, such as Trypanosoma cruzi, ${ }^{38}$ rubella virus, adenovirus, herpes simplex, cytomegalovirus, Epstein-Barr virus, influenza, para-influenza, and parvovirus, ${ }^{22}$ but none has been documented in the right ventricular myocardium itself. Why inflammatory lesions are mainly confined to the right ventricle remains to be clarified. It is noteworthy that some experimental forms of myocarditis are limited exclusively to the right ventricle. Matsumori and Kawai reported selective right ventricular perimyocarditis in coxsackie $B$ virus infected $\mathrm{BALB} / \mathrm{c} \mathrm{mice}^{39}$; in a later stage this led to wall thinning and right ventricular aneurysms with gross and histological pictures similar to those seen in human ARVC. ARVC presents with a broad spectrum of clinical features and different substrates: whether a single pathogenetic mechanism or several genetic and/or environmental factors account for the same elective right ventricular involvement remains to be elucidated.

We used nested PCR to examine the presence of enteroviral genomes in the myocardial tissue of 20 patients with clinically and histologically confirmed ARVC. The method used enables the detection of low copy numbers of targets, and is useful when small amounts of tissue are available. At least two frozen and/or four formalin fixed endomyocardial biopsies were analysed by nested PCR to avoid false negatives as a result of insufficient infected material. Recently, some authors have reported that studies using single biopsies produce consistently lower estimates for enterovirus than studies that examine multiple biopsies. ${ }^{40}$

However, the failure to reveal enteroviral sequences in our samples, which were both frozen and formalin fixed, might be explained by a lower sensitivity of PCR as a result of extraction of RNA combined with RT. RNA molecules are highly labile because of the presence of ubiquitous endogenous and exogenous ribonucleases. This is particularly true for viral RNA. The yield of viral RNA available for RT-PCR is influenced by several factors such as tissue preservation, fixation, the thickness of paraffin wax embedded sections, and the protocols used for RNA extraction and RT. However, the protocols for RNA extraction and RT that we used have improved the sensitivity of this technique, and it is now possible to detect virus genomes using paraffin wax embedded material. ${ }^{28} 29$

Our study is the first prospective study investigating the role of enterovirus in a consecutive series of both familial and nonfamilial patients with ARVC. Despite the very high sensitivity of the technique and the number of processed sample biopsies, positive signals were not obtained in any of the 20 patients with ARVC. To the best of our knowledge there are only four published reports that 
have investigated the presence of enteroviruses in the myocardium of patients with ARVC. ${ }^{21-24}$ One was an adult patient and was considered a false positive because the sequenced PCR product was identical to that of the positive control, a finding consistent with cross contamination. ${ }^{21}$ Two were children and both studies were negative. ${ }^{22}$ More recently, Heim and colleagues ${ }^{23}$ and Grumbach and colleagues $^{24}$ studied patients with a clinical diagnosis of ARVC; enterovirus RNA was detected by nested PCR in $50 \%$ and $37.5 \%$, respectively. However, the accuracy of the clinical diagnoses is questionable because there was no family history, and the onset of first symptoms occurred at mean age of 59 years, with a mean history duration of only 45 and 15 months, respectively. The possibility that myocardial infection might have been merely incidental in the setting of a systemic viral infection cannot be excluded.

With regard to our negative findings, we can rule out the possibility of the virus having been eliminated because we included patients with both recent onset and chronic disease. We cannot exclude the possibility that an infective aetiopathogenesis with viruses other than those investigated might be involved and these should be searched for.

Recently, apoptosis has been shown to be a mechanism accounting for progressive myocyte death in ARVC in both postmortem ${ }^{17}$ and biopsy ${ }^{18}$ material. Whether this mode of death is related to the presence of viral infection or is simply caused by other triggers, such as an internal genetic clock, remains to be clarified.

Infiltrating cytotoxic $\mathrm{T}$ cells, usually present after viral infection, can induce either necrosis or apoptosis in a target cell depending on the apoptotic factors present in that cell. ${ }^{41}$ Some pro-apoptotic proteins, such as the Bcl2 homologue Bax, Fas, and Fas ligand, and several anti-apoptotic factors, including $\mathrm{Bcl} 2$, have now been identified. Some authors have demonstrated that, despite pronounced inflammatory activity, myocyte apoptosis is rare in experimental coxsackie virus myocarditis, and the myocardial inflammation is associated with increased cytoplasmic expression of $\mathrm{Bcl} 2$ protein. ${ }^{42}$

Therefore, future molecular studies should look for the presence of other infective agents already known to trigger apoptosis. ${ }^{43-45}$

This work was supported by Target Project, Veneto Region, Venice, and MURST, Rome, Italy.

1 Richardson P, McKenna WJ, Bristow, et al. Report of the $1995 \mathrm{WHO} / \mathrm{ISFC}$ task force on the definition and classification of cardiomyopathies. Circulation 1996;93:841-2.

2 Marcus FI, Fontaine GH, Guiraudon G, et al. Right ventricular dysplasia. A report of 24 adult cases. Circulation 1982;65:384-98

3 Nava A, Rossi L, Thiene G, eds. Arrhythmogenic right ventricular cardiomyopathy/dysplasia. Amsterdam: Elsevier, 1997.

4 Basso C, Thiene G, Corrado D, et al. Arrhyhmogenic right ventricular cardiomyopathy. Dysplasia, dystrophy or myocarditis?. Circulation 1996;94:983-91.

5 Thiene G, Nava A, Corrado D, et al. Right ventricular cardiomyopathy and sudden death in young people. $N \mathrm{Engl} f$ Med 1988; 318:129-33.

6 Corrado D, Thiene G, Nava A, et al. Sudden death in young corrado D, Thiene G, Nava A, et al. Sudden death in young cases. Am ₹ Med 1990;89:588-96.

7 Thiene G, Nava A, Angelini A, et al. Anatomoclinical aspects of arrhythmogenic right ventricular cardiomyopa- thy. In: Baroldi G, Camerini F, Goodwin JF, eds. Advances in cardiomyopathies. Berlin: Springer-Verlag, 1990:397-408.

8 Virmani R, Rabinovitz M, Clark MA, et al. Sudden death and partial absence of the right ventricular myocardium: a report of three cases and a review of the literature. Arch Pathol Lab Med 1982;106:163-7.

9 Nava A, Scognamiglio R, Thiene G, et al. A polymorphic form of familial arrhythmogenic right ventricular dysplasia. Am 7 Cardiol 1987;59:1405-9.

10 Nava A, Thiene G, Canciani B, et al. Familial occurrence of right ventricular dysplasia. A study involving nine families. 7 Am Coll Cardiol 1988;12:1222-8.

11 Rampazzo A, Nava A, Danieli GA, et al. The gene for arrhythmogenic right ventricular cardiomyopathy maps to chromosome 14q23-q24. Hum Mol Genet 1994;3:959-62.

12 Rampazzo A, Nava A, Erne P, et al. A new locus for arrhythmogenic right ventricular cardiomyopathy (ARVD2) maps to chromosome 1q42-q43. Hum Mol Genet 1995;11:21514.

13 Rampazzo A, Nava A, Miorin M, et al. ARVD4, a new locus for arrhythmogenic right ventricular cardiomyopathy, maps to chromosome 2 long arm. Genomics 1997;45:259-63.

14 Severini GM, Krajinovic M, Pinamonti B, et al. A new locus for arrhythmogenic right ventricular dysplasia on the long arm of chromosome 14. Genomics 1996;31:193-220.

15 Ahmad F, Duanxiang Li, Karibe A, et al. Localization of a gene responsible for arrhythmogenic right ventricular dysplasia to chromosome 3p23. Circulation 1998;98:2791-5.

16 Coonar AS, Protonotarios N, Tsatsopoulou A, et al. Gene for arrhythogenic right ventricular cardiomyopathy with diffuse nonepidermolytic palmoplantar keratoderma and woolly hair (Naxos disease) maps to $17 \mathrm{q} 21$. Circulation 1998;97:2049-58.

17 Mallat Z, Teddgui A, Fontaliran F, et al. Evidence of apoptosis in arrhythmogenic right ventricular dysplasia. $N$ Engl f Med 1996;335:1190-6.

18 Valente M, Calabrese F, Thiene G, et al. In vivo evidence of apoptosis in arrhythmogenic right ventricular cardiomyopathy. Am f Pathol 1998;152:479-84.

19 Thiene G, Corrado D, Nava A, et al. Right ventricular cardiomyopathy: is there evidence of an inflammatory aetiology? Eur Heart 7 1991;12 (suppl D):22-5.

20 Wooddruff JF. Viral myocarditis. A review. Am 7 Pathol 1980;101:427-529.

21 Giacca M, Severini GM, Mestroni L, et al. Low frequency of detection by nested polymerase chain reaction of enterovirus ribonucleic acid in endomyocardial tissue of patients with idiopathic dilated cardiomyopathy. $\mathcal{F} \mathrm{Am}$ Coll Cardiol 1994;24:1033-40.

22 Kearney DL, Towbin JA, Bricker T, et al. Case 5 familial right ventricular dysplasia (cardiomyopathy). Pediatr Pathol Lab Med 1995;15:181-9.

23 Heim A, Grumbach I, Hake S, et al. Enterovirus heart disease of adults: a persistent limited organ infection in the presence of neutralizing antibodies. $\mathcal{F}$ Med Virol 1997;53: 196-204.

24 Grumbach IM, Heim A, Vonhof S, et al. Coxsackie virus genome in myocardium of patients with arrhythmogenic right ventricular dysplasia/cardiomyopathy. Cardiology 1997; 15:241-5.

25 Khan M, Why H, Richardson PJ, et al. Nucleotide sequencing of PCR products shows the presence of coxsackie-B3 virus in endomyocardial biopsies from patients with myocarditis or dilated cardiomyopathy. Biochem Soc Trans 1994;22:176S

26 McKenna WJ, Thiene G, Nava A, et al. Diagnosis of arrhythmogenic right ventricular dysplasia arrhythmogenic right ventricular

27 Angelini A, Basso C, Nava A, et al. Endomyocardial biopsy in arrhythmogenic right ventricular cardiomyopathy. Am Heart f 1996;132:203-6.

28 Martin AB, Webber S, Fricker J, et al. Acute myocarditis. Rapid diagnosis by PCR in children. Circulation 1994;90: 330-9.

29 Griffin LD, Kearney D, Ni J, et al. Analysis of formalin-fixed and frozen myocardial autopsy samples for viral genome in childhood myocarditis and dilated cardiomyopathy with enilocardial fibroelastosis using polymerase chain reaction (PCR). Cardiovasc Pathol 1995;4:3-11.

30 Chomczynski P, Sacchi N. Single step method of RNA isolation by guanidium thiocyanate-phenol-chloroform extraction. Anal Biochem 1987;162:156-9.

31 Ercolani L, Florence B, Denaro M, et al. Isolation and complete sequence glyceraldehyde-3-phosphate dehydrogenase gene. F Biol Chem 1988;263:15335-41.

32 Minor PD. Growth, assay and purification of picornaviruses. In: Mahy BWJ, ed. Virology. A practical approach. Oxford: IRL Press, 1985:25-41.

33 Taswell C. Limiting dilution assays for the determination of immunocompetent cell frequencies. F Immunol 1981;126: 1614-19

34 Severini GM, Mestroni L, Falaschi A, et al. Nested polymerase chain reaction for high-sensitivity detection of enteroviral RNA in biological samples. F Clin Microb 1993; 31:1345-9.

35 Blomström-Lundqvist C, Sabel KG, Olsonn SB. The longterm follow-up of 15 patients with arrhythmogenic right ventricular dysplasia. Br Heart $\mathcal{7}$ 1987;58:477-88.

36 Pinamonti B, Miani D, Sinagra G, et al. Familial right ventricular dysplasia with biventricular involvement and inflammatory infiltrates. Heart 1996;76:66-9. 
37 Sabel KG, Blomström-Lundqvist C, Olsson SB, et al. Arrhythmogenic right ventricular dysplasia in brother and Arrhythmogenic right ventricular dysplasia in brother and
sister: is it related to myocarditis? Pediatr Cardiol 1990;11: sister: is

38 Rossi MA. Comparison of Chagas' heart disease to arrhythmogenic right ventricular cardiomyopathy. Am Heart $\mathcal{F}$ 1995;129:113-16

39 Matsumori A, Kawai C. Coxsackie virus B3 perimyocarditis in $\mathrm{BALB} / \mathrm{c}$ mice: experimental model of chronic perimyocarditis in the right ventricle. $\mathcal{F}$ Pathol 1980;131:97-107.

40 Jeffery S, Kelling PJ, Luskaszyk A, et al. Molecular evaluation of enteroviruses in the pathogenesis of idiopathic dilated cardiomyopathy. Clin Cardiol 1997;20:85763.
41 Cohen JJ, Duke RC, Fadok VA, et al. Apoptosis and programmed cell death in immunity. Annu Rev Immunol

42 Colston JT, Chandrasekar B, Freeman GL. Expression of apoptosis-related proteins in experimental coxsackie virus myocarditis. Cardiovasc Res 1998;38:158-68.

43 Hardwick JM. Virus induced apoptosis. Adv Pharmacol 1997;41:295-336. 44 Marcellus RC, Lavoie JN, Boivin D, et al. The early region 4
orf4 protein of human adenovirus type 5 induces p53-independent cell death by apoptosis. $\mathcal{F}$ Virol 1998;72: $7144-53$.

45 O'Brien V. Viruses and apoptosis. F Gen Virol 1998;79: 